\title{
Comparison of three caval reconstruction techniques in orthotopic liver transplantation: result from a university hospital from Bangkok, Thailand
}

Tatsana Uthaithammarat, Methee Sutherasan, Bunthoon Nonthasoot, Wipusit Taesombat, Athaya Vorasittha, Supanit Nivatvongs, Boonchoo Sirichindakul

Department of Surgery, Faculty of Medicine, Chulalongkorn University, Bangkok, Thailand

Background: In orthotopic liver transplantation, three caval reconstruction techniques are commonly being performed worldwide. These are conventional, piggyback technique and side-to-side cavocaval anastomosis (STSCCA). Each has its own advantages and drawbacks. Herein we report the result from our hospital comparing the three techniques.

Methods: We retrospectively reviewed the detail of orthotopic liver transplantations performed in our hospital from January 2008 to March 2020. Data being collected were type of caval reconstruction, blood loss, operative time, ischemic time, length of intensive care unit stay and total hospital stay, and several immediate and early postoperative complications

Results: In the given period, 11 conventional, 89 piggyback and 119 STSCCA caval reconstruction were done. There were no statistically significant difference in blood loss, operative time, cold ischemic time, length of intensive care unit stay and hospital stay. The STSCCA has the lowest warm ischemic time (40 minutes) followed by the piggyback technique (43 minutes) and the conventional technique (47 minutes) $(\mathrm{P}<0.001)$. Regarding postoperative complications, there were no statistically significant difference in rate of primary nonfunction, early allograft dysfunction, reperfusion syndrome, hepatic artery/portal vein/biliary complication or rate of acute kidney injury. The rate of acute cellular rejection in STSCCA was lowest (2.63\%) followed by conventional $(9.09 \%)$ and piggyback technique $(12.5 \%)(P=0.024)$. The outflow complication rate was indifference between three groups (conventional $9.09 \%$, piggyback $0 \%$, and STSCCA $1.75 \%, P=0.466$ )

Conclusions: Our study has showed no difference in outflow obstruction rate among three techniques. The choice for reconstruction should rely on the preference of each institute and the suitability of each patient. However, STSCCA may provide the lowest warm ischemic time.

Corresponding author: Tatsana Uthaithammarat

E-mail: gonkpai@gmail.com

(c) The Korean Society for Transplantation

This is an Open Access article distributed under the terms of the Creative Commons Attribution Non-Commercial License (http://creativecommons.org/licenses/by-nc/4.0/) which permits unrestricted non-commercial use, distribution, and reproduction in any medium, provided the original work is properly cited. 